\title{
Estrutura produtiva e encadeamentos produtivos na era das cadeias globais de valor: uma análise insumo-produto
}

\author{
Kaio Glauber Vital da Costa \\ Marta dos Reis Castilho \\ Martín Puchet Anyul
}

\section{Área temática 1.4: Indústria e competitividade - Padrões de especialização produtiva e desenvolvimento}

Resumo: Este estudo analisa a relação entre o grau e os de participação nas cadeias globais de valor (CGV) e seus impactos sobre a complexidade das estruturas produtivas para um conjunto de países disponíveis na base World Input-Output Database (WIOD). Para tanto, analisam-se as participações nas CGV, a complexidade das estruturas produtivas e os vínculos (padrões) das relações intersetoriais das três economias entre 1995 e 2011. Argumentamos que o grau e o padrão de articulação intersetorial determinam a forma e a intensidade da inserção dos países nas CGV. O presente estudo apresenta duas contribuições: i) mostra um novo indicador de complexidade estrutural e ii) oferece evidência empírica demonstrando que a participação nas CGV depende do grau de complexidade estrutural e essa relação é não-linear entre os países.

Palavras-chave: Estrutura produtiva; mudança estrutural; cadeias globais de valor; complexidade estrutural

\begin{abstract}
This paper analyzes the relationship between the degree of participation in global value chains and its impacts on the complexity of productive structures for a set of countries available in the World Input-Output Database (WIOD). We first consider the share in the GVC, the complexity of productive structures, and the links (patterns) of the inter-sectoral relations of the economies between 1995 and 2011. To do so, this paper uses the WIOD, a world input-output table, as an alternative trade measure to analyze the role of three newly industrialized economies. We argue that the degree and the pattern of inter-sectoral articulation determine the form and the intensity of the insertion of the countries in the GVC. The present paper presents two contributions: i) shows a new indicator of structural complexity and ii) offers empirical evidence demonstrating that participation in GVC depends on the degree of structural complexity and this relationship is non-linear between countries.
\end{abstract}

Keywords: Productive structure; structural change; global value chains; structural complexity

JEL Classification: L16; C67; F1 


\section{Introdução}

Um único automóvel Honda é feito de 20.000 a 30.000 partes produzidas por milhares de diferentes setores e empresas dispersos geograficamente. A revolucionária ideia de Henry Ford, cujo sonho de total auto-suficiência na produção de automóveis foi realizado em sua indústria localizada na confluência dos rios Rouge e Detroit (Estados Unidos), mostrou-se limitada em termos históricos (Bartelme e Gorodnichenko, 2015). Com o passar das décadas, porém, a ideia de integrar verticalmente todas as etapas do processo produtivo mostrou-se cada vez mais inadequada aos objetivos das empresas transnacionais (ETNs). Os ganhos de produtividade passaram a depender cada vez mais da divisão internacional do trabalho entre empresas, que comercializam insumos intermediários com outras empresas em uma rede complexa de relações comerciais.

Impulsionada pela interação de diversas transformações ocorridas entre as décadas de 1980 e $1990^{1}$, a fragmentação e a dispersão geográfica dos processos produtivos conectaram países em distintos estágios de desenvolvimento. Esses dois fenômenos impulsionaram um intrincado arcabouço relacional no qual comércio internacional, serviços de suporte às atividades centrais das empresas ("core competences") e investimento direto estrangeiro (IDE) são atualmente em grande parte indissociáveis. O processo de fragmentação produtiva supõe que as indústrias atravessem vários países e disseminem tarefas e sub-processos nos distintos países. Estas transformações no comércio internacional impõem compreender as transações interindustriais como um conjunto de fluxos que se dividem em segmentos situados em diversos países. Nesse contexto, não apenas a produção voltada ao mercado doméstico requer uma proporção cada vez maior de insumos importados, mas também o conteúdo importado das exportações aumentou ao longo das últimas duas décadas.

As CGV são governadas pelas ETNs que coordenam as decisões de oferta e montagem de partes, peças e acessórios (ou insumos intermediários) entre os diversos países, estabelecendo, assim, encadeamentos inter-setoriais entre esses países. Essa mudança na organização da produção foi condicionada em grande medida pelas estratégias microeconômicas de internacionalização e gestão das cadeias de valor e de produção das $\operatorname{ETNs}^{2}$ (Sarti e Hiratuka, 2010; Medeiros e Trebat, 2017). O resultado dessas estratégias foi o deslocamento de etapas dos processos produtivos dos países desenvolvidos (PD) para os países em desenvolvimento (PED), alterando a geografia mundial dos fluxos de comércio, de produção e de investimento direto estrangeiro (IDE).

A transferência de etapas dos processos produtivos para os PED provocou um crescimento na participação desses países no produto industrial global (UNCTAD, 2015), refletindo o deslocamento de parte das atividades das ETNs dos países industrializados para esses países. Contudo, o resultado em termos de capacidade de gerar processos de transformação estrutural e de crescimento econômico foi diferente para os diferentes países e regiões. Essas diferenças entre os PED refletem não apenas o grau de participação nas CGV, mas principalmente a forma com a qual os países se inserem nas cadeias. A magnitude dos benefícios extraídos por uma economia de sua inserção externa depende em grande medida do grau de encadeamento do setor exportador com o restante da economia doméstica. Maiores serão os benefícios em termos de renda e de empregos (de

\footnotetext{
${ }^{1}$ A abertura comercial da China, particularmente a sua entrada na Organização Mundial do Comércio (OMC), em 2001, e a dissolução da URSS, no começo da década de 1990, adicionaram milhões de pessoas ao mercado de trabalho, com salários relativamente menores em comparação aos países desenvolvidos. Isto coincidiu com a adoção de medidas de liberalização comercial na forma de acordos bilaterais e regionais, como o Tratado de libre comercio de América del Norte, Mercado comun del Sur e ASEAN, por exemplo. Além disso, os avanços nas tecnologias da informação e da comunicação (TICs) resultaram em uma diminuição nos custos de coordenação e de transporte. Como resultado desses desenvolvimentos, o comércio em insumos intermediários cresceu a taxas superiores ao comércio de bens e serviços finais (Boddin, 2016).

${ }^{2}$ Estas estratégias guardam forte conexão com o processo recente de financeirização das empresas, que impõe objetivos financeiros de maximização de lucros associado, entre outros, à redução de ativos e à concentração nas atividades associadas a seus "núcleos de competência” (Milberg e Winkler, 2013).
} 
maior qualificação), quanto maior for a capacidade deste setor de gerar encadeamentos com a economia doméstica.

Em um contexto de processos produtivos fragmentados e formação de $\mathrm{CGV}$, um aspecto muitas vezes negligenciado pela literatura de comércio exterior diz respeito aos impactos provocados pelo aumento do conteúdo importado sobre o nível de interdependência entre os setores domésticos. Diante da diversidade de formas de inserção das economias em desenvolvimento nas CGV, faz-se necessário estudar como os diferentes padrões e capacidades de inserção dos PED no sistema internacionalizado de produção se refletiram no padrão de inserção comercial e na estrutura produtiva dessas três economias. Essas três economias foram escolhidas devido às suas importâncias relativas e seus diferentes posicionamentos dentro das CGV. O padrão assimétrico de inserção dessas economias nas CGV permite mostrar como estruturas produtivas com diferentes níveis de complexidade estrutural ajudam a compreender os diferentes padrões de inserção.

Se os países em desenvolvimento apresentam diferentes padrões de inserção nas CGV, resultado combinado das decisões microeconômicas das ETNs e das estratégias de política econômica desses países, cabe perguntar: em que medida estruturas produtivas historicamente determinadas influenciam e são influenciados pelos diferentes padrões de inserção nas CGV? Para Meng et al. (2017), Lopez-Gonzalez, Meliciani e Savona (2016). e Beverelli et al. (2016), a resposta à esta pergunta depende do grau de encadeamento ou de interdependência entre os setores domésticos no sentido formulado originalmente por Hirschman (1961) ${ }^{3}$. Para os autores anteriormente mencionados, as cadeias produtivas domésticas constituem o fundamento a partir do qual os países se inserem nas várias etapas das CGV. Em outras palavras, os níveis de integração doméstica entre e dentro dos setores podem explicar uma parcela relevante da atual variação da participação das economias em desenvolvimento nas CGV.

$\mathrm{O}$ artigo está estruturado em mais três seções, além desta introdução e das conclusões. $\mathrm{Na}$ seção 2, são revisitados os principais aspectos apontados pela literatura para explicar as diferentes participações dos países nas CGV, procurando enfatizar a importância da complexidade da estrutura produtiva para a inserção externa dos países. A seção 3 mostra a base de dados que utilizaremos para construir os indicadores utilizados no presente estudo: indicadores de encadeamentos para trás e para frente na matriz doméstica e nas $\mathrm{CGV}$, o índice de complexidade estrutural, assim como os indicadores desenvolvidos a partir do método de redes para analisar as estruturas produtivas internas das três economias. Na seção 4 são apresentados os principais resultados do estudo, mostrando as assimetrias nas participações do Brasil, da China e do México nas CGV.

\section{A complexidade estrutural como um aspecto particular da articulação interindustrial}

A conectividade é a característica principal da análise insumo-produto e há, como esperado, muitas maneiras de medí-la, desde os estudos pioneiros de Chenery e Watanabe (1958), Rasmussen (1956) e Hirschman (1961) até os modelos mais sofisticados, tais como as medidas de interdependência de Yan e Ames (1965), a transactions rounds matrix de Robinson e Markandya (1973), a medida de ciclicidade de Finn (1976) e a medida de autovalor dominante de Dietzenbacher (1992). Entre os mais recentes exemplos de medidas de interdependência, mostrando o ressurgimento do interesse por esse tipo de pesquisa, estão o comprimento das cadeias produtivas de Romero, Dietzenbacher e Hewings (2009) e a complexidade como uma medida de interdependência

\footnotetext{
${ }^{3}$ Para Hirschman (1961), os encadeamentos entre os setores são divididos em dois tipos: i) encadeamentos para trás, quando um setor demanda insumos intermediários de outros setores, e ii) encadeamentos para frente, quando um setor oferta insumos intermediários a serem utilizados na produção de outros bens.
} 
entre os setores de Amaral et al. (2007) ${ }^{4}$. Esses estudos estão preocupados principalmente com o nível de articulação ou deinterdependência entre os setores e as análises dos multplicadores setoriais.

De acordo com Basu e Johson (1994), os vários métodos para desenvolver índices a partir das matrizes de insumo-produto podem ser classificados como:

1. Índices baseados nas matrizes de fluxos interindustriais;

2. Índices baseados em matrizes de booleanas;

3. Índices baseados na matriz inversa de Leontief;

4. Índices baseados em abordagens mistas.

Uma vez que a análise interindustrial se ocupa das interrelações necessárias à produção de bens e serviços, a função primordial da análise estrutural é investigar o curso das correntes de bens e serviços em sua sequência de um setor a outro da estrutura. Assim, o interesse da análise estrutural, desde suas primeiras formulações com Leontief (1985), foi a construção de indicadores que permitissem entender a arquitetura das estruturas produtivas dos países. Ou seja, qual é a dominância de um setor em relação a outro (Hurwicz e Leontief, 1955; Leontief, 1985)? Os setores são mais ou menos auto-suficientes, interdependentes e/ou dependentes entre eles (Sonis e Hewings, 1998)? A estrutura produtiva está mais ou menos conectada com os fluxos de bens e serviços demandados de outras economias (Sonis e Hewings, 2001)?

Dentro dessa abordagem de análise estrutural, Wong (1954) sugere que o determinante da matriz de coeficientes técnicos $\Delta=(I-A)$ é uma medida relativa do volume da produção líquida e da complexidade do sistema produtivo. A abordagem proposta por Lantner $(1972,1974)$ também parte da interpretação dos determinantes da matriz $(I-A)$, mas tem como base os teoremas propostos por Bott e Mayberry (1954). A partir do estudo dos determinantes de matrizes de relações interindustriais ou comerciais, Lantner (1972, 1974), Gazon (1976) e Lantner e Lebert $(2013,2015)$ elaboram o conceito de circularidade estrutural. O índice de circularidade estrutural busca medir o nível de interdependência entre todo um conjunto de indústrias em um sistema econômico ou entre países/regiões no comércio internacional.

Do ponto de vista quantitativo, o determinante tem a vantagem de ser um indicador sintético que mostra o arranjo interno da estrutura dos setores produtivos ou dos vínculos comerciais entre regiões ou países, isto é, da posição e da intensidade das conexões entre os setores e/ou países. Já do ponto de vista qualitativo, permite interpretar a complexidade das estruturas produtivas como o resultado do gradual processo de expansão da rede de interdependências hierárquicas entre setores da economia. Ademais, é possível realizar uma análide de decomposição estrutural a partir do cálculo dos determinantes, de modo a calcularmos as taxas de interdependência, de dependência e de autarquia das economias ${ }^{6}$.

Formalmente, o índice de circularidade ou de complexidade estrutural é definido como ice $=\frac{(1-\Delta)}{\Delta}$. O índice de complexidade estrutural é um indicador da quantidade de circuitos de retroalimentação que existem entre os setores de uma economia. A presença dos circuitos de

\footnotetext{
${ }^{4}$ Esse autores utilizam o termo "complexidade econômica" como o resultado do desenvolvimento das economias, que amplia a multiplicidade das interdependências dentro de um sistema econômico. Sonis e Hewings (1998) definem como o resultado do gradual processo (ou propriedade emergente) de complexificação da rede de interdependências entre os setores econômicos, atividades econômicas e todos os possíveis sub-sistemas econômicos e espaciais. Uma vez que esses estudos utilizam principalmente a abordagem de insumo-produto para analisar os fluxos de trocas presentes nas economias e como uma forma de diferenciar a noção de complexidade econômica presente em Hidalgo et al. (2007) e Gala (2017), é mais apropriado a utilização da noção de complexidade estrutural. A utilização desse termo é também mais apropriada porque o objetivo principal desses indicadores baseados em matrizes de insumo-produto é, de modo geral, medir o grau de interdependência entre os setores que compõem a estrutura produtiva de uma economia.

${ }^{5}$ Uma matriz booleana é uma matriz formada apenas pelos valores 0 e 1 , sendo que 0 indica a inexistência de fluxos entre dois elementos quaisquer em uma matriz de trocas e 1 mostra a existência de fluxos entre esses elementos.

${ }^{6}$ Um critério para estimar, a priori, a importância relativa dos setores de uma estrutura produtiva pode ser formulado determinando-se os sub-determinantes da nova estrutura sem o respectivo setor extraído. Essa extração permite verificar quantitativa e qualitativamente a importância de um setor no processo de intermediação dos fluxos de bens e serviços.
} 
retroalimentação indica que as relações entre os setores produtivos são mais densas e que os setores estão mais integrados entre si. A estrutura produtiva fica mais complexa e desenvolvida à medida em que o número de circuitos de retroalimentação aumenta em relação a todos os circuitos que unem todos os setores (Puchet, 1996).

Quando uma estrutura produtiva torna-se mais complexa, no sentido de que todo setor depende cada vez mais dos demais setores como fornecedores de insumos para sua produção, a demanda intermediária aumenta como proporção do produto total e cresce a geração de efeitos de retroalimentação entre os setores. Como apontado por Aroche-Reyes (1993), o índice de complexidade estrutural não depende do tamanho dos coeficientes técnicos, $a_{i j}$, mas da complexidade da estrutura produtiva, definida pela presença de circuitos de retroalimentação entre os setores ou do nível de integração entre os setores. Ao contrário do indicador de complexidade econômica elaborado por Hidalgo et al. (2007), que toma como dado o grau de interdependência entre os setores da estrutura produtiva ${ }^{7}$ para analisar a complexidade econômica a partir dos produtos exportados pelos países, o índice de complexidade estrutural é elaborado exatamente a partir da matriz de trocas entre os setores produtivos de uma economia. Essa abordagem permite um melhor entendimento do grau de interdependência entre os setores de uma economia ou de sua complexidade estrutural, uma vez que lança luz sobre o nível de articulação presente na estrutura produtiva.

\section{Base de dados e metodologia}

Esta seção resume a metodologia subjacente ao cálculo das medidas utilizadas para avaliar a participação dos países nas CGV - conteúdo importado presente nas exportações -, os encadeamentos para trás e para frente a partir do método average propagation lengths (APL) e o índice global de circularidade. A base de dados utilizada para a construção desses indicadores são as tabelas de insumo-produto mundiais para o período de 1995-2011, que foram construídas no projeto World Input-Output Database (WIOD) ${ }^{8}$. Essas são tabelas de insumo-produto multi-países, cobrindo 35 setores e 40 países mais o resto do mundo.

\subsection{Valor adicionado estrangeiro contido nas exportações}

O conceito de comércio em valor adicionado parte da ideia de que para produzir um produto para exportação é necessário combinar valor adicionado doméstico e estrangeiro em diferentes proporções. Por sua vez, essas exportações podem ser incorporados em outros produtos, como insumos intermediários, ou consumidas como bens finais. Uma das principais características da atual fase do processo de globalização da produção é crescente presença de insumos intermediários importados nas exportações. Além disso, o valor adicionado doméstico incluído nas exportações pode circular por vários outros países incorporado em insumos intermediários utilizados ao longo da cadeia de produção e, nesse processo, parte dele retornar à economia doméstica.

\footnotetext{
${ }^{7}$ Os autores assumem, pelo menos implicitamente, que o índice de complexidade econômica, baseado no valor bruto das exportações e no conceito de vantagens comparativas reveladas, é uma boa proxy para a complexidade da estrutura produtiva. Contudo, essa relação entre estrutura da pauta exportadora e estrutura produtiva merece ser ponderada por duas qualificações: i) em um ambiente de processos produtivos fragmentados e CGV, a participação do valor adicionado estrangeiro contido nas exportações é elevada para alguns países, notadamente os países melhor posicionados nessas CGV (China, Coreia do Sul, Malásia, México, Hungria e República Tcheca, por exemplo), de modo que uma fração não desprezível da complexidade econômica de um país pode refletir a complexidade econômica de outro país incorporada em suas exportações; e ii) países de grandes dimensões e ricos em recursos naturais, como o Brasil e a Rússia, por exemplo, podem possuir uma pauta exportadora pouco complexa, mas uma estrutura produtiva complexa do ponto de vista de suas articulações ou interdependências setoriais, o que pode indicar uma baixa capacidade dos setores domésticos em competir no mercado internacional.

${ }^{8}$ Ver Dietzenbacher et al. (2013).
} 
Nesse contexto, a medida de comércio em valor adicionado implica em alocar o valor adicionado ao longo da CGV para cada produtor, país ou região, requerendo matrizes de insumoproduto com informações sobre todos os fluxos bilaterais de insumos intermediários e bens e serviços finais. A disponibilidade das matrizes multi-países levou a várias contribuições metodológicas em termos de criação de indicadores de comércio em valor adicionado, isto é, medidas de participação nas CGV. Alguns estudos recentes generalizam o conceito de especialização vertical de Hummels, Ishii e Yi (2001) e capturam diferentes dimensões do fluxo internacional de valor adicionado. A contribuições iniciais foram realizadas por Daudin, Rifflart e Schweisguth (2011), Johnson e Noguera (2012) e Koopman, Wang e Wei (2014). O valor adicionado estrangeiro contido nas exportações é parte desta última geração de indicadores e pode ser decomposto em nível bastante detalhado em termos setoriais.

De acordo com Dietzenbacher (2013), para medir a especialização vertical, a nível de países, deve ser utilizado dois indicadores: i) as importações necessárias para realizar as exportações e ii) o valor adicionado necessário para realizar as exportações. Uma forma de dar uma escala relativa a estes indicadores, usualmente se divide o valor das importações e a quantidade do valor adicionado sobre o total de exportaçoes da economia. Assim, suas formas funcionais são:

$$
V S=\frac{s^{\prime} M(I-A)^{-1} e}{s^{\prime} e} \quad \text { (1) e } V A=\frac{w^{\prime}(I-A)^{-1} e}{s^{\prime} e}
$$

Onde $s^{\prime}$ é um vetor soma unitário, $M$ a matriz de insumos importados, $e$ o vetor coluna das exportaçoes, $w^{\prime}$ o vetor linha do valor adicionado, $e$ são as exportações e $(I-A)^{-1}$ a inversa de Leontief.

A soma de VS e VA é igual a 1, o que significa que o valor das exportações se decompõe entre valor adicionado estrangeiro (correspondente às importações necessárias para a produção das exportações) e valor adicionado doméstico. Em termos formais, temos que:

$$
V S+V A=\frac{\left(s^{\prime} M+w^{\prime}\right)(I-A)^{-1} e}{s^{\prime} e}=\frac{s^{\prime}(I-A)(I-A)^{-1} e}{s^{\prime} e}=1
$$

\subsection{Os indicadores de encadeamentos para trás e para frente a partir do método average propagation lengths}

Em geral, as matrizes de insumo-produto mostram que cada setor vende determinada proporção de sua produção a outros setores, assim como consome outra proporção dessa produção. Assim, cada setor estabelece uma relação com os demais setores presentes nas matrizes. O método average propagation lengths proposto por Romero, Dietzenbacher e Hewings (2009) serve para medir o comprimenro da cadeia de produção dos setores ou a distância entre os setores. Segundo esses autores, tomando a abordagem dos encadeamentos para trás, o APL mede, por exemplo, o número médio de encadeamentos (ou de passos) necessários para que um aumento na demanda final por hotéis e restaurantes se propague por todos os setores e chegue até a agricultura. Isso significa dizer que o APL estima o comprimento das cadeias de produção ligando os setores.

Deixe $z_{i j}$, um elemento qualquer da matriz $Z$, denotar a venda de insumos intermediários domésticos do setor $i$ ao setor $j$. O elemento típico $f_{i}$ do vetor coluna $f$ denota a demanda final pelos bens e serviços produzidos pelo setor $i$. O elemento $r_{i}$ do vetor linha $r$ fornece os insumos primários (custos do trabalho, depreciação do capital, excedente operacional bruto e importações). As duas equações contábeis fornecem:

$$
\begin{gathered}
x=Z s+f \\
x^{\prime}=s^{\prime} Z+r^{\prime}
\end{gathered}
$$


Onde $x$ é o vetor linha de valor bruto da produção para cada setor e $s$ um vetor coluna composto apenas por 1 .

Da perspectiva dos encadeamentos para trás, defina os coeficientes de insumo ou técnicos como $a_{i j}=\frac{z_{i j}}{x_{j}}$ ou em notação matricial como $A=Z \hat{x}^{-1}$, onde $\hat{x}$ denota a matriz diagonal com os elementos do vetor $x$ em sua diagonal principal. O coeficiente $a_{i j}$ indica o insumo do setor $i$ que é necessário na produção do setor $j$. Esse coeficiente também reflete o encadeamento para trás ou a dependência do setor $j$ em relação aos insumos do setor $i$. Utilizando os coeficientes técnicos, o sistema contábil da equação 3 pode reescrito da seguinte forma:

$$
x=A x+f(3.1)
$$

de modo que a solução é

$$
x=(I-A)^{-1} f=L f(6) .
$$

Onde $L=(I-A)^{-1}$ é a inversa de Leontief. Se os coeficientes técnicos permanecem constantes, um aumento em $\Delta f$ na demanda final requer que a produção aumente em $\Delta x=L(\Delta f)$. Conforme mostrado a seguir, o elemento $l_{i j}$ fornece o produto (extra) no setor $i$ que é necessário para satisfazer um aumento (extra), por unidade de reais, da demanda final no setor setor $j$. A expansão da série de potência da inversa de Leontief, isto é, $L=(I-A)^{-1}=I+A+A^{2}+A^{3}+$ $\cdots$, resulta então $\Delta x=L(\Delta f)=\left(I+A+A^{2}+A^{3}+\cdots\right) \Delta f$. O aumento total na produção do setor $i$, devido ao aumento na demanda final no setor $j(i \neq j)$, por unidade monetária, fornece:

$$
\Delta x_{i}=l_{i j}=a_{i j}+\sum_{k} a_{i k} a_{k j}+\sum_{k} \sum_{m} a_{i k} a_{k m} a_{m j}+\cdots
$$

O primeiro termo do lado direito da expressão expressa o efeito direto, enquanto os termos termos refletem os efeitos indiretos. Por exemplo, $a_{i k} a_{k j}$ reflete o efeito indireto, em dois estágios, que ocorre por meio do setor $k$. Ou seja, o aumento na demanda final no setor $j$ aumentará a produção do setor $k$ por $a_{k j}$, o qual requer insumos (e uma produção extra) extras do setor $i$. Isso vale para cada setor $k$, de modo que $\sum_{k} a_{i k} a_{k j}$ gera efeitos indiretos, em dois estágios, entre os setores $i$ e $j$. No caso de $i=j$, o efeito inicial também deve ser incluído, porque a demanda final extra deve, primeiramente, ser produzida para auto-consumo dos setores. Nesse caso, a equação 7 torna-se:

$$
\Delta x_{j}=l_{j j}=1+a_{i j}+\sum_{k} a_{j k} a_{k j}+\sum_{k} \sum_{m} a_{j k} a_{k m} a_{m j}+\cdots
$$

Então, o APL entre os setores $i$ e $j$ pode ser derivado. Se a demanda final no setor $j$ aumenta em um unidade monetária, o produto no setor $i$ é afetado por $\Delta x_{i}=l_{i j}$. Da equação 7, temos que a participação $\frac{a_{i j}}{l_{i j}}$ requer um estágio, a participação $\frac{\sum_{k} a_{j k} a_{k j}}{l_{i j}}$ requer dois estágios, a participação $\frac{\sum_{k} \sum_{m} a_{i k} a_{k m} a_{m j}}{l_{i j}}$ três estágios e assim por diante. O número médio de estágios que toma o aumento na demanda final no setor $j$ para afetar o produto no setor $i$, torna-se 


$$
\frac{\left(1 \times a_{i j}+2 \times \sum_{k} a_{j k} a_{k j}+3 \times \sum_{k} \sum_{m} a_{j k} a_{k m} a_{m j}\right)}{l_{i j}}
$$

No caso de $i=j$, podemos aplicar um raciocínio similar. Um aumento em uma unidade monetária na demanda final do setor $j$ resulta em um aumento no produto deste setor de $\Delta x_{j}-1=$ $l_{i j}-1$. Utilizando a equação 8, temos:

$$
\frac{\left(1 \times a_{j j}+2 \times \sum_{k} a_{j k} a_{k j}+3 \times \sum_{k} \sum_{m} a_{j k} a_{k m} a_{m j}\right)}{\left(l_{j j}-1\right)}
$$

Note que o numerador nas equações 8 e 8.1 é dado pelos elementos $(i, j)$ e $(j, j)$ da matriz $H=1 \times A+2 \times A^{2}+3 \times A^{3}+\cdots=\sum_{t=1}^{\infty} t A^{t}$. Se pre-multiplicarmos $H$ por $(I-A)$, temos $(I-A) H=A+A^{2}+A^{3}+\cdots=L-I$. Portanto, $H=L(L-I)$. O indicadeores APL são obtidos como $\frac{h_{i j}}{l_{i j}}$, para $i \neq j$, e $\frac{h_{j j}}{\left(l_{j j}-1\right)}$.

Do ponto de vista dos encadeamentos para trás, os coeficientes de produção são definidos como $b_{i j}=\frac{z_{i j}}{x_{i}}$ (ou $B=\hat{x}^{-1} Z$ ). Esta razão representa a proporção do produto do setor $i$ que é vendida ao setor $j$, refletindo a dependência direta da indústria $i$ em relação às compras do setor $j$. A equação 3.1 pode ser reescrita como $x^{\prime}=x^{\prime} B+r^{\prime}$ e sua solução é $x^{\prime}=r^{\prime}(I-B)^{-1}=r^{\prime} G$, sendo $G=$ $(I-B)^{-1}$. Este modelo é conhecido como orientado pela ofertado, proposto por Gosh (1958).

O elemento $g_{i j}$ da inversa de Gosh, $G=(I-B)^{-1}$, reflete a dependência total do setor $i$ em relação ao setor $j$. Na derivação do APL entre os setores $i$ e $j$, considere um aumento nos custos primários do setor $i$ por uma unidade monetária. O valor do produto no setor $j$ aumenta por $\Delta x_{j}=g_{i j}=b_{i j}+\sum_{k} b_{i k} b_{k j}+\sum_{k} \sum_{m} b_{i k} b_{k m} b_{m j}+\cdots$. O primeiro termo do lado direito dá o efeito direto, o segundo termo é o efeito indireto em dois estágios, o terceiro termo é o efeito indireto em três estágios e assim por diante. O número médio de estágios necessários para que ocorra a difusão entre os setores $i$ e $j$ é dado por:

$$
\frac{\left(1 \times b_{i j}+2 \times \sum_{k} b_{j k} b_{k j}+3 \times \sum_{k} \sum_{m} b_{j k} b_{k m} b_{m j}\right)}{g_{i j}}
$$

O numerador pode ser escrito como $\tilde{h}_{i j}$, com $\widetilde{H}=G(G-I)$, e os APL são dados por $\frac{\widetilde{h}_{i j}}{g_{i j}}$. Quando $i=j$, os APL são dados por $\frac{\widetilde{h}_{j j}}{\left(g_{j j}-1\right)}$.

Quando consideramos as distâncias de um setor a qualquer outro setor na estrutura produtiva, devemos tomar as médias. Isto pode ser feito tanto da perspectiva dos encadeamentos para frente, quanto dos encadeamentos para trás. Assim,

$$
F A_{i}=\frac{1}{n} \sum_{j=1}^{n} A P L_{i j}
$$

e o encadeamento para trás ponderado é dado por:

$$
B A_{j}=\frac{1}{n} \sum_{i=1}^{n} A P L_{i j}
$$


Onde $n$ é igual ao número de setores, que no presente estudo é $n=34$.

Finalmente, a média geral dos APLs pode ser utilizada como um índice para medir a complexidade das estruturas produtivas. Esse índice de complexidade é calculado da seguinte maneira:

$$
C I=\frac{1}{n^{2}} \sum_{i=1}^{n} \sum_{j=1}^{n} A P L_{i j}=\frac{1}{n} \sum_{i=1}^{n} F A_{i}=\frac{1}{n} \sum_{j=1}^{n} B A_{j}
$$

Segundo Romero, Dietzenbacher e Hewings (2009), os APLs têm uma aplicação direta para medir os efeitos da fragmentação sobre a complexidade estrutural das economias. Por um lado, a dispersão geográfica da produção induz a uma relocalização de etapas, processos e tarefas para outros países. As cadeias produtivas que anteriormente estavam localizadas em um único país são fragmentadas e realizadas em diferentes países dispersos geograficamente. Consequentemente, a complexidade estrutural e as interdependências setoriais tendem a diminuir no país que perde parte dos das cadeias produtivas. Por outro lado, nos países que atraíram novas atividades, a complexidade estrutural, o tamanho dos efeitos indiretos e o comprimento da cadeia de produção podem aumentar, desde que essas novas atividades possuam encadeamentos com as empresas domésticas.

\subsection{0 índice de circularidade global}

Wong (1954) sugere que o determinante da matriz de coeficientes técnicos $(I-A)$ é uma medida relativa do volume da produção líquida e da complexidade do sistema de trocas. A abordagem proposta por Lantner (1972) e Lantner e Lebert $(2013$, 2015) também parte da interpretação dos determinantes da matriz $(I-A)$. O determinante da matriz $(I-A)$ aparece como uma função da composição ou do arranjo interna da estrutura, isto é, da posição e da intensidade das ligações entre os setores que compõem a estrutura de trocas. Esta abordagem permite avançar na noção de complexidade estrutural, entendida como o resultado do processo de expansão da rede de interdependências entre os setores econômicos e todos os possíveis subsistemas econômicos.

A ideia é a de que um choque exógeno na demanda final pelo produto do setor $i$ se propagará entre todos os setores, até chegar ao setor $k$, por exemplo, da estrutura produtiva mediante uma série de influências diretas e indiretas. Nesse sentido, à medida em que uma economia torna-se mais complexa, os circuitos de influências e de encadeamentos entre os setores também tornam-se mais complexos. Assim, a complexidade estrutural é caracterizada principalmente pelos efeitos de retroalimentação entre os setores ou pelos efeitos circulares exercidos pelas influências, de demanda e de oferta, recíprocas entre os setores. Então, o índice de complexidade estrutural é uma medida do peso que as relações circulares ou de retroalimentação têm em uma estrutura produtiva. Sua maior magnitude relativa mostra que a economia incorporou mais caminhos de retroalimentação, mas relações circulares em um circuito de trocas (Álvarez e Puchet, 2015).

$\mathrm{O}$ índice de circularidade global é calculado como

$$
i c g=\frac{(1-\Delta)}{\Delta}
$$

Onde $\Delta$ é o determinante da matriz $(I-A)$.

Considere a seguinte rede representativa de uma estrutura produtiva hipotética com três setores: agricultura, indústria e serviços. Como podemos observar, a característica principal desta simples estrutura produtiva é a circularidade no fluxo de bens e serviços entre os três setores. Por 
circularidade queremos dizer que a demanda realizada pela agricultura à indústria deve ser atendida mediante a demanda que a indústria exerce sobre o setor de serviços. Além disso, os serviços também necessitam de insumos da agricultura. Somado a esses efeitos lineares temos os efeitos de retroalimentação entre os setores, isto é, a agricultura demanda da indústria, que, por sua vez, também demanda agricultura, o mesmo ocorrendo com as demais relações. Por fim, uma parte da produção dos setores é auto-consumida nos próprios setores. A complexidade estrutural está relacionada com o maior peso dessas relações circulares ou dos efeitos de retroalimentação na estrutura produtiva.

\section{Figura 1 - Rede representativa de uma estrutura produtiva com três setores}

Fonte: elaboração própria

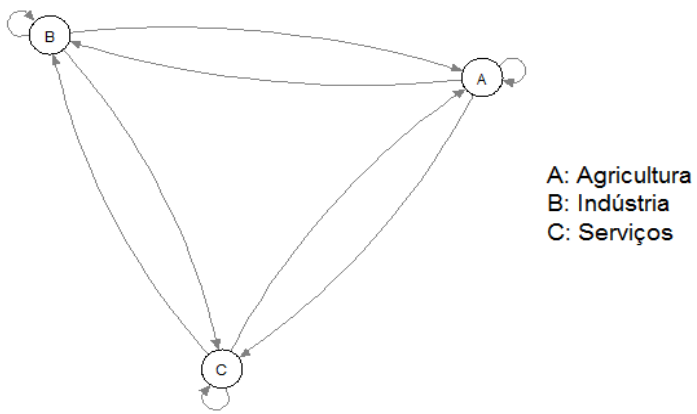

\section{Encadeamentos e complexidade estrutural na era das cadeias globais de valor}

De acordo com Puchet e Solís (2013), a discussão sobre os processos de industrialização posterior ao período de industrialização por substituição de importações se bifurcou em duas rotas. $\mathrm{Na}$ América Latina, se associou ao esgotamento do padrão de crescimento liderado pelo Estado e que a nova divisão internacional do trabalho, surgida depois do segundo choque do petróleo, em 1979, conduziria a região a um processo de perda de densidade das estruturas produtivas ou de elos em várias cadeias produtivas. Nos países de industrialização tardia, como a Coreia do Sul e a China, a industrialização foi considerada como resultado do padrão de crescimento liderado pelas exportações de manufaturas de alta intensidade tecnológica.

Os estudos sobre a participação do três países nas CGV apontam para dois diferentes graus e padrões de participação, em nível global ou setorial (Castilho e Puchet, 2012; Canuto, Fleischhaker e Schellekens, 2015; Hermida, 2016). Além disso, quando o caso do Brasil é analisado comparativamente a outras economias em desenvolvimento da Ásia ou mesmo de outras economias da América Latina, como o México, percebe-se uma baixa participação do país nas CGV.

O gráfico 1 mostra como a participação do México nas redes de produção e de valor é uma das maiores entre os 16 países selecionados ${ }^{9}$, ficando atrás apenas de três países asiáticos (Taiwan, Coreia do Sul e China). Já o Brasil, em conjunto com o Japão, apresenta os menores valores para o conjunto de países analisados. A participação do Brasil cresce entre 1995 e 2000 de $7.9 \%$ para $11,9 \%$, respectivamente, caindo para $10.9 \%$ em 2011. Esses resultados revelam que a crise de 2008 teve o efeito de reduzir o conteúdo importado contido nas importações brasileiras. A participação do

\footnotetext{
${ }^{9}$ Preferimos calcular o índice de especialização vertical para 16 dos 40 países presentes na base WIOD, pois esse procedimento permite uma melhor análise dos três países. Esse método possui dois problemas: i) perda de informação e ii) viés de seleção. Contudo, dado o objetivo do presente estudo, a análise comparada entre Brasil, China e México, a utilização da base WIOD para 16 países visa apenas colocar em perspectiva, com outras economias desenvolvidas e em desenvolvimento, as três economias.
} 
México tem dois períodos diferentes: i) 1995-2000, no qual há um crescimento de $27.35 \%$ para $34.4 \%$ e ii) $2005-2011$, período que mostra uma queda no índice de $33 \%$ para $31.7 \%$. Esses são fatos estilizados dentro da literatura sobre redes globais/regionais de produção e de produção e a participação dos dois países nessas redes.

\section{Gráfico 1 - Conteúdo importado contido nas exportações, países selecionados - (em $\%$ do total exportado)}

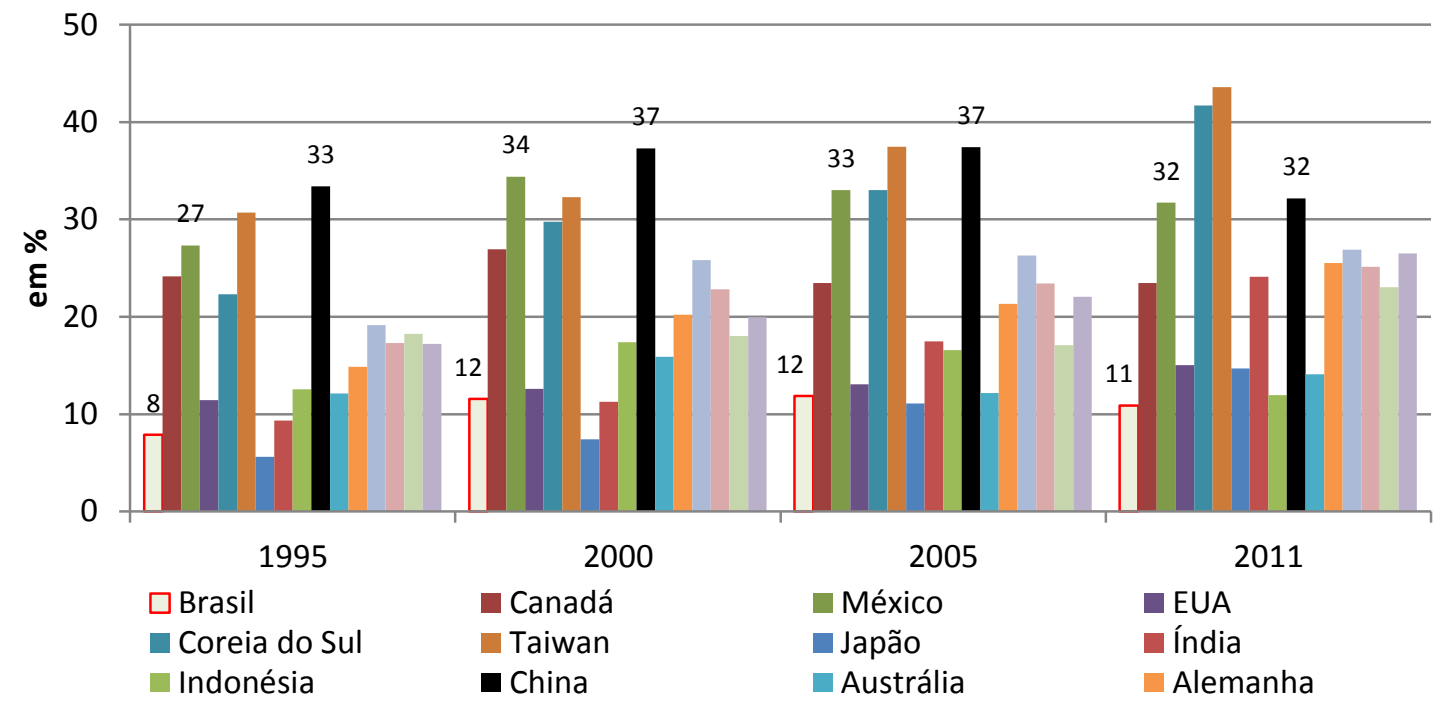

Fonte: elaboração própria a partir de dados da WIOD.

No gráfico 2, relacionamos o grau de especialização vertical e o índice de circularidade em um ponto no tempo, o ano de 2011. O objetivo é duplo: i) colocar o Brasil, a China e o México em uma perspectiva mais ampla, dado que a especialização vertical é um fenômeno envolvendo países desenvolvidos e em desenvolvimento, e ii) avançar na análise da relação entre comércio exterior e complexidade estrutural. Nesse gráfico, é possível perceber uma relação não-linear entre as duas variáveis, indicando que não necessariamente um maior conteúdo importado nas exportações diminui a complexidade estrutural das economias. Ou seja, ser mais complexo do ponto do peso das relações circulares não implica, per se, em um menor peso das importações contido nas exportações.

A relação não-linear entre as variáveis assume um formato de U. Isso indica a existência de diferentes grupos de países com diferentes relações entre a especialização vertical e a complexidade estrutural. A linha no Gráfico 2 ajuda a mostrar como prevalece dois diferentes padrões para as variáveis em análise. Os países localizados no lado esquerdo são caracterizados por um menor peso das relações circulares com níveis relativamente elevados de especialização vertical. Os países do lado direito apresentam uma relação aparentemente positiva entre as duas variáveis, ou seja, quanto maior a especialização vertical, maior o peso das relações circulares.

Como podemos observar, os três países analisados estão localizados em diferentes posições o gráfico. O México (MEX) está posicionado na parte descendente da curva, indicando que o peso das relações circulares é baixo, enquanto apresenta uma elevada participação nas CGV. Por sua vez, o Brasil (BRA) conforma um cluster muito específico com Estados Unidos (EUA), Austrália (AUS), Rússia (RUS) e Indonésia (IDN), países caracterizados pela dimensão continental e pela forte dotação de recursos naturais. Esses são países que apresentam um nível relativamente elevado de complexidade estrutural com uma baixa participação nas $\mathrm{CGV}$, sendo o Brasil o país com a menor participação em nossa amostra de 40 países. Já a China (CHN) parece conformar outro cluster com a Coreia do Sul (COR) e o Japão (JAP), caracterizados pela elevada complexidade de suas estruturas produtivas e de uma também elevada participação nas CGV. 
Os resultados são importantes na medida em que mostram uma relação não-linear em formato de U entre o índice global de circularidade e a participação nas CGV. Por exemplo, a China e o México, ainda que estejam em diferentes estágios de desenvolvimento econômico ${ }^{10}$, possuem níveis relativamente parecidos de participação nas CGV, embora apresentem diferentes pesos das relações circulares em suas estruturas produtivas. Isso indica, por um lado, que a estrutura produtiva de países como China e Coreia do Sul conseguem demandar uma grande quantidade de insumos intermediários importados sem provocar perdas significadas no peso das relações circulares. Mas, por outro lado, em países como o México uma maior participação nas CGV ocorre em detrimento das relações circulares em sua estrutura produtiva. Em outras palavras, os resultados ajudam a entender como as importações de insumos intermediários afetam de forma desigual as relações circulares existentes nas respectivas estruturas produtivas.

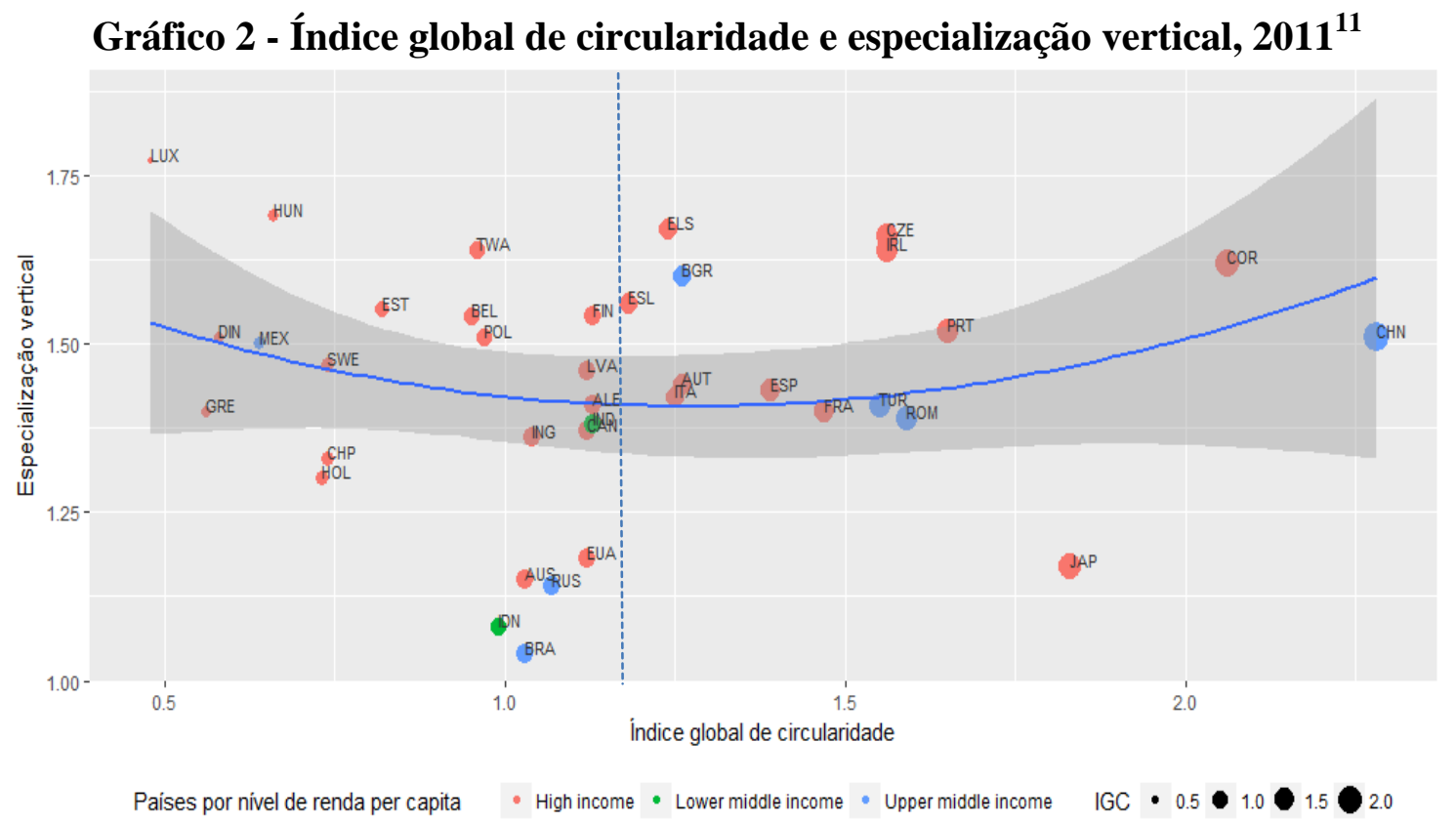

Fonte: elaboração própria a partir de dados da WIOD.

OBS: os valores estão em logarítimos.

Os efeitos da especialização vertical e da fragmentação produtiva sobre os países podem ser analisados no gráfico 3 abaixo, que mostra como evoluiu o índice de circularidade global dos 40 países presentes na base WIOD. É interessante notar que, enquanto Brasil e México perdem em termos de complexidade estrutural, a China mostra a maior taxa de crescimento entre todos os países. Entre 1995 e 2011, o índice global de circularidade cresceu aproximadamente 50\% na China. Para o Brasil e o México, as diminuições foram de $23 \%$ e $30 \%$, respectivamente. No total, 25 países ganharam em termos de complexidade estrutural e 15 países tiveram quedas nos pesos das relações circulares em suas estruturas produtivas. Esses resultados lançam luz no debate sobre os efeitos da fragmentação produtiva nas estruturas produtivas dos diversos países envolvidos nas CGV.

\footnotetext{
${ }^{10}$ Em 2011, o PIB per capita (em US\$ correntes) da China era de aproximadamente US\$ 5.600, enquanto o do México era de US\$ 9.700. O PIB per capita do Brasil era de US\$13.000.

${ }^{11} \mathrm{O}$ ajuste da curva foi realizado a partir da função loess, presente no software $R$, que consiste em um método de suavizar a curva. A vantagem desse método em relação aos demais, como o smoothing Splines ou simple Local Linear Regression, é a sua maior flexibilidade de aplicação. A função loess é computada por meio de uma regressão de minímios quadrados ponderada localmente. Isto é, para o ajuste no ponto $x$, o ajuste é feito utilizando pontos em um vizinhança de $x$, ponderada por suas distâncias em relação à $x$. Nesse sentido, loess é um função de ajuste polinimial, na qual o ajuste da curva está contido no intervalo $[0, \infty]$. Quanto maior o valor atribuído ao ajuste, mais informações serão utilizadas para o ajuste da curva.
} 
$\mathrm{O}$ recente interesse nas $\mathrm{CGV}$ como um mecanismo para o potencial desenvolvimento econômico parece ter centrado a maior parte dos estudos nos aspectos globais sem levar em consideração, de maneira adequada, a importância da complexidade das estruturas produtivas para uma participação mais dinâmica nas CGV. Em um ambiente de crescente fragmentação produtiva e maior penetração de insumos intermediários importados, a complexidade estrutural depende da geração de vínculos entre as novas empresas que se instalam no país e as empresas domésticas. No caso dos países que perderam complexidade estrutural, como o Brasil e o México ${ }^{12}$, é possível afirmar que essa queda esteja relacionada a ausência de encadeamentos entre as empresas entrantes e as empresas domésticas já instaladas.

Vale notar, que as três grandes economias asiáticas ganharam em termos de complexidade estrutural, ao mesmo tempo em que aumentaram o grau de participação nas CGV. Esses resultados sugerem que as respectivas os setores desses países passaram a depender mais dos insumos importados para realizar as suas produções sem diminuir a complexidade de suas estruturas produtivas. Esse "padrão asiático", marcadamente diferente do padrão latinoamericano representado pelo Brasil e pelo México, indica que a complexidade estrutural depende da forma pela qual a importação de insumos intermediários não seja um substituto da produção local, mas que gere encadeamentos com a produção doméstica.

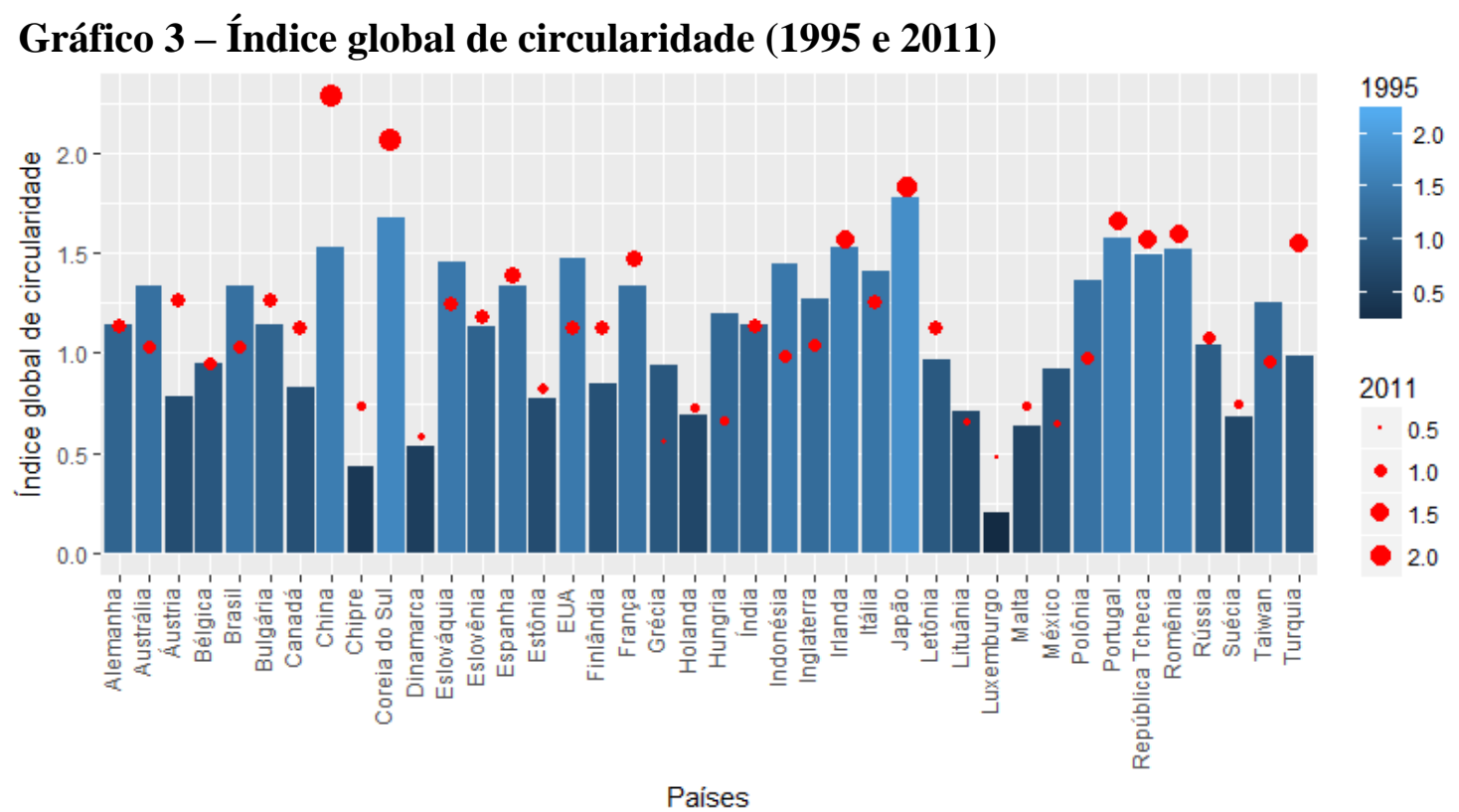

Fonte: elaboração própria a partir de dados da WIOD.

O gráfico 4 procura agrupar e hierarquizar os países a partir da maior ou menor similaridade entre a especialização vertical e o índice de circularidade. Ser similar nesses grupos indica apenas quão próximos um dos outros estão os países. A ideia de proximidade utiliza, então, a noção de distância estatística (euclidiana) para agrupar os países em clusters. Dado o par de variáveis especialização vertical e índice global de circularidade, o Gráfico 4 hierarquiza os países segundo a proximidade estatística entre ambas as variáveis para os diferentes países. A leitura correta é no sentido anti-horário, começando dos mais similares Coreia do Sul (COR) e China (CHN) e terminando na Romênia (ROM) e Turquia (TUR).

\footnotetext{
${ }^{12}$ A análise conjunta do Canadá, dos Estados Unidos e do México, países que conformam o Tratado de Libre Comercio de América del Norte (TLCAN) mostra que apenas o Canadá ganhou em termos de complexidade estrutural (29\%), enquanto o México e os Estados Unidos perderam, respectivamente, 28\% e 35\%. Esses resultados revelam que os efeitos do TLCAN mais a participação nas CGV beneficiaram apenas o Canadá em termos de complexidade estrutural.
} 
É possível perceber que os países em desenvolvimento estão agrupados em diferentes clusters. O Brasil, como dito mais acima, está agrupado com outros países de dimensões continentais que apresentam baixa especialização vertical e moderada complexidade estrutural. Já o México está agrupado com os países que apresentam níveis similares de especialização vertical, embora com significativa heterogeneidade nos níveis de complexidade estrutural. Dentro do seu cluster, em vermelho, o Brasil está relativamente mais próximo à Indonésia (IDN) do que aos Estados Unidos (EUA), Austrália (AUS) e Rússia (RUS), enquanto no cluster em verde, o México é mais similar à Dinamarca (DIN) do que da Polônia (POL). Esse cluster é composto em sua maioria por países do leste e do norte da Europa. A China (CHN) forma um cluster com a Coreia do Sul (COR), indicando que ambos os países são os mais similares em termos de índice de especialização vertical e de circularidade global.

\section{Gráfico 4 - Agrupamento dos países segundo a similaridade entre os índices de especialização vertical e o de circularidade global, $2011^{13}$}

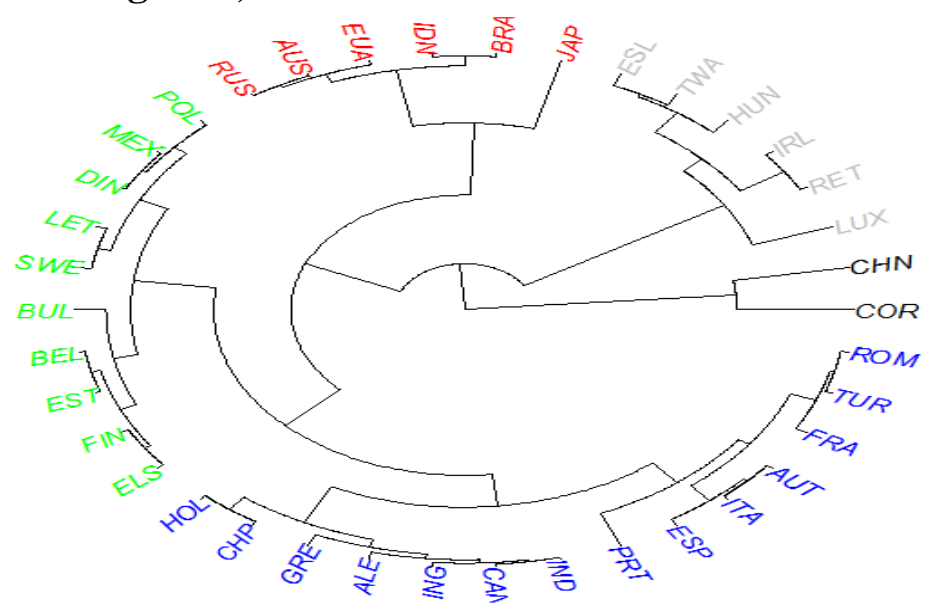

Fonte: elaboração própria a partir de dados da WIOD.

A literatura sobre as CGV raramente avança no entendimento dos impactos da crescente fragmentação produtiva sobre a complexidade das estruturas produtivas. Contudo, é possível supor que uma das consequências dessa dispersão geográfica dos processos produtivos seja uma mudança concomitante na estrutura de interdependência entre os setores domésticos (Romero, Dietzenbacher e Hewings, 2009). Isso porque as relações circulares, como por exemplo a relação circular carvão-açoequipamentos de mineração-carvão, existentes no interior das estruturas produtivas são parcialmente perdidas pela maior presença de insumos importados.

Uma forma de avaliar como a evolução da participação dos três países nas CGV afetou suas estruturas produtivas é por meio da análise dos encadeamentos para trás e para frente pelo método APL. Como podemos ver na tabela 1 , os encadeamentos médios na economia chinesa são maiores do que aqueles verificados nas economias brasileira e mexicana. Em 2011, o APL médio da China era de 2.73, enquanto os do Brasil e do México eram, respectivamente, 1.96 e 1.66. Isso significa que o comprimento das cadeias produtivas chinesas são maiores vis-à-vis àqueles do Brasil e do México. Em outras palavras, dado um choque exógeno na demanda final de um bem, esse choque demorará

\footnotetext{
${ }^{13}$ Para a elaboração dos clusters utilizamos dois procedimentos. O primeiro foi o cálculo das distâncias euclidianas, que define a similaridade entre dois elementos ou variáveis $(x, y)$. A distância pelo método euclidiano pode ser calculada como $d_{e u c}(x, y)=\sqrt{\sum_{i=1}^{n}\left(x_{i}-y_{i}\right)^{2}}$. Esse primeiro procedimento fornece uma matriz de distâncias entre as duas variáveis. A partir dessa matriz de distâncias, podemos realizar o segundo procedimento, a formação dos clusters hierárquicos a partir do método Ward (utilizamos o método ward.D2 do pacote "ape", contido no software $R$ ). O método de Ward utiliza como distância a soma dos quadrados entre os dois agrupamentos.
} 
mais tempo para se propagar por toda a estrutura produtiva chinesa do que em relação às outras duas economias. Esses resultados corroboram com o índice global de circularidade, o qual mostrou que a estrutura produtiva chinesa era relativamente mais complexa do que as estruturas produtivas do Brasil e do México.

Vale lembrar, que o foco da atenção muda do tamanho dos efeitos entre os setores para a distância entre os setores. A ideia de distância é a de medir o comprimento das cadeias produtivas, isto é, o número de setores envolvidos para a produção de determinado produto ou serviço. Nesse sentido, uma cadeia produtiva que envolve uma maior quantidade de setores está sujeita a maiores efeitos de retroalimentação e apresentar um maior peso das relações circulares.

De um ponto de vista geral, os setores fornecedores de matérias-primas possuem os maiores APLs, tanto em relação aos encadeamentos para frente (forward), quanto em relação aos encadeamentos para trás (backward). Isso ocorre porque esses setores estão localizados no início dos processos produtivos, de modo que é esperado que o comprimento de suas cadeias produtivas seja relativamente maior relativamente aos demais setores. Já os setores de comércio, serviço e administração pública apresentam os menores APLs, com algumas poucas exceções, como hoteis e restaurantes, atividades imobiliárias (Brasil e México) e outros transportes (China).

Tabela 1 - Índices de encadeamentos para trás e para frente (average propagation lengths) 2011

(continua)

\begin{tabular}{|c|c|c|c|c|c|c|}
\hline & \multicolumn{2}{|c|}{ Brasil } & \multicolumn{2}{|c|}{ China } & \multicolumn{2}{|c|}{ México } \\
\hline Setores & $\begin{array}{c}\text { Forward } \\
-2011 \\
\end{array}$ & $\begin{array}{c}\text { Backward } \\
-2011 \\
\end{array}$ & $\begin{array}{c}\text { Forward } \\
-2011 \\
\end{array}$ & $\begin{array}{c}\text { Backward } \\
-2011 \\
\end{array}$ & $\begin{array}{c}\text { Forward } \\
-2011 \\
\end{array}$ & $\begin{array}{c}\text { Backward } \\
-2011 \\
\end{array}$ \\
\hline Agricultura, floresta, caça e pesca & 2.22 & 2.44 & 2.71 & 3.42 & 1.80 & 2.26 \\
\hline Indústrias extrativas e mineração & 1.83 & 2.58 & 2.50 & 3.35 & 1.63 & 2.32 \\
\hline Alimentos, bebidas, tabaco & 2.13 & 2.12 & 2.88 & 3.00 & 1.73 & 1.72 \\
\hline Têxteis e produtos têxteis & 2.11 & 2.09 & 3.20 & 3.11 & 1.69 & 1.68 \\
\hline Couro e calçados & 2.01 & 2.22 & 3.09 & 3.53 & 1.81 & 1.77 \\
\hline Madeira e produtos da madeira & 2.16 & 2.33 & 2.99 & 3.30 & 1.81 & 1.98 \\
\hline Celulose, papel, impressão e publicação & 1.88 & 1.95 & 2.81 & 2.89 & 1.60 & 1.62 \\
\hline Coque, petróleo refinado e comb. Nuc & 2.45 & 1.89 & 2.95 & 2.73 & 2.12 & 1.65 \\
\hline Produtos químicos & 1.92 & 2.09 & 2.71 & 3.02 & 1.69 & 1.63 \\
\hline Plástico e borracha & 1.94 & 1.79 & 2.98 & 2.97 & 1.55 & 1.53 \\
\hline Fabricação de produtos não-metálicos & 1.90 & 2.20 & 2.63 & 2.98 & 1.55 & 1.57 \\
\hline Metais básicos & 2.07 & 2.21 & 2.88 & 3.42 & 1.70 & 1.72 \\
\hline Máquinas e equipamentos, nec & 2.02 & 2.02 & 2.85 & 2.91 & 1.60 & 1.51 \\
\hline Equipamentos elétricos e óticos & 1.93 & 2.00 & 2.98 & 3.13 & 1.59 & 1.58 \\
\hline Equipamentos de transporte & 2.07 & 2.22 & 3.01 & 2.87 & 1.63 & 1.53 \\
\hline Outras manufaturas; reciclagem & 1.92 & 2.04 & 2.68 & 2.77 & 1.53 & 1.42 \\
\hline Eletricidade, gás e água & 2.20 & 1.87 & 2.96 & 3.12 & 1.78 & 1.58 \\
\hline Construção & 1.99 & 2.06 & 2.70 & 2.54 & 1.63 & 1.56 \\
\hline $\begin{array}{l}\text { Venda, manutenção e reparação de veículos } \\
\text { automóveis e motocicletas }\end{array}$ & 1.87 & 1.65 & 3.57 & 0.03 & 1.57 & 1.50 \\
\hline Comércio por atacado & 1.87 & 1.65 & 2.44 & 2.48 & 1.52 & 1.42 \\
\hline Comércio por varejo & 1.87 & 1.65 & 2.44 & 2.48 & 1.53 & 1.42 \\
\hline Hoteis e restaurantes & 2.35 & 1.85 & 2.76 & 2.41 & 1.64 & 1.53 \\
\hline Transporte terrestre & 1.76 & 1.78 & 2.49 & 2.55 & 1.56 & 1.43 \\
\hline Transporte marítimo & 1.76 & 1.78 & 2.68 & 2.84 & 1.69 & 1.47 \\
\hline Outros transportes & 1.76 & 1.78 & 2.61 & 2.41 & 1.58 & 1.51 \\
\hline
\end{tabular}


Tabela 1 - Índices de encadeamentos para trás e para frente (average propagation lengths) 2011

\begin{tabular}{l|ll|r|rrr}
\multicolumn{1}{c}{ conclusão } \\
\hline Correios e telecomunicações & 1.76 & 1.78 & 2.52 & 2.40 & 1.56 & 1.50 \\
Intermediação financeira & 1.76 & 1.78 & 2.58 & 2.46 & 1.75 & 1.67 \\
Atividades imobiliárias & 2.07 & 1.82 & 2.56 & 2.50 & 1.86 & 1.55 \\
Aluguel de Máquinas e equipamentos & 1.96 & 1.93 & 2.47 & 2.57 & 1.72 & 1.64 \\
Administração pública & 1.76 & 1.78 & 2.50 & 2.53 & 1.54 & 1.54 \\
Educação & 1.91 & 1.78 & 2.32 & 2.44 & 1.59 & 2.37 \\
Saúde e ação social & 1.86 & 1.99 & 2.31 & 2.49 & 1.63 & 1.78 \\
Outras atividades de serviços coletivos, & 1.76 & 1.78 & 2.38 & 2.48 & 1.54 & 1.87 \\
sociais e pessoais & $\mathbf{1 . 9 6}$ & $\mathbf{1 . 9 6}$ & $\mathbf{2 . 7 3}$ & $\mathbf{2 . 7 3}$ & $\mathbf{1 . 6 6}$ & $\mathbf{1 . 6 6}$ \\
\hline Média & & &
\end{tabular}

Fonte: elaboração própria a partir de dados da WIOD.

A tabela 2 mostra o comprimento médio das cadeias produtivas de 10 países desenvolvidos e em desenvolvimento. Como no caso do índice global de circularidade, os países asiáticos e latinoamericanos apresentaram diferentes comportamentos. Por um lado, diminuíram a complexidade estrutural e o comprimento médio de suas cadeias produtivas do Brasil e do México, ao mesmo tempo em que, por outro lado, aumentaram a complexidade estrutural e o comprimento médio das cadeias produtivas de países como China, Coreia do Sul e Japão. Esses resultados reforçam a percepção de que ambas as regiões possuem diferentes padrões de articulação entre a estrutura produtiva e o comércio exterior.

A leitura conjunta do índice global de circularidade e do comprimento médio das cadeias produtivas (APLs) permite entender como as respectivas estruturas produtivas dos países se comportaram em um ambiente de fragmentação produtiva. Para China, Coreia do Sul, Japão e Canadá, por exemplo, o maior peso das relações circulares ou dos efeitos de retroalimentação entre os setores resultou em um aumento do comprimento médio das estruturas produtivas. Isso parece indicar que estruturas produtivas mais complexas do ponto de vista do índice global de circularidade possuem cadeias produtivas mais longas, de modo que a propagação de um choque exógeno demoraria mais tempo para impactar todos os setores nessas economias. Já nas estruturas produtivas menos complexas, um choque exógeno atingiria mais rapidamente o conjunto de setores dessas economias.

Tabela 2 - Taxa de crescimento dos APLs para países selecionados - 1995 e 2011 (em \%)

\begin{tabular}{lrrr}
\hline Países & $\mathbf{1 9 9 5}$ & $\mathbf{2 0 1 1}$ & Taxa de crescimento (\%) \\
\hline China & 2.38 & 2.73 & $15 \%$ \\
Canadá & 1.79 & 1.93 & $8 \%$ \\
Coreia do Sul & 2.21 & 2.36 & $6 \%$ \\
Japão & 2.24 & 2.25 & $1 \%$ \\
Índia & 2.03 & 2.03 & $0 \%$ \\
Brasil & 2.00 & 1.96 & $-2 \%$ \\
Itália & 2.04 & 1.99 & $-3 \%$ \\
Alemanha & 1.86 & 1.81 & $-3 \%$ \\
México & 1.76 & 1.66 & $-6 \%$ \\
Estados Unidos & 2.14 & 1.98 & $-8 \%$ \\
\hline
\end{tabular}

Fonte: elaboração própria a partir de dados da WIOD. 


\section{Conclusões}

Este artigo analisou a relação entre a complexidade das estruturas produtivas e a participação dos países desenvolvidos e em desenvolvimento nas cadeias globais de valor e de produção. O presente estudo buscou contribuir metodologica e empiricamente para a literatura de comércio exterior e estrutura produtiva a partir da exposição do índice global de circularidade. $\mathrm{O}$ objetivo deste índice é medir o peso das relações circulares ou dos efeitos de retroalimentação entre os setores. A vantagem dessse índice em relação aos demais, como, por exemplo, as diversas versões dos índices de encadeamentos para trás e para frente, é ser suficientemente sintético levando em consideração toda a rede de interações, direta e indiretas, entre os setores, assim como o autoconsumos dos mesmos. Além disso, é possível realizar uma decomposição desse índice em outros indicadores (interdependência, dependência e autarquia).

Desde o começo da década de 1990, as cadeias globais de valor e a fragmentação dos processos produtivos tornaram-se fenômenos mais disseminados entre os países desenvolvidos e em desenvolvimento. Essa globalização da produção implicou no deslocamento de plantas industriais e alguns serviços dos países desenvolvidos para os países em desenvolvimento, notadamente os asiáticos, promovendo uma maior interdependência entre as estruturas produtivas desses países e uma mudança nos padrões de comércio exterior.

Essa dispersão geográfica da produção resultou em desempenhos assimétricos entre os países em termos de ganhos e perdas de complexidade estrutural, com uma nítida diferenciação entre os padrões asiático e latinoamericano. De um lado, Brasil e México apresentaram um aumento no grau de participação nas cadeias globais de valor e uma queda na complexidade estrutural, enquanto, por outro lado, países como China, Coreia do Sul e Japão aumentaram suas participações nas cadeias globais de valor ao mesmo tempo em que houve também um aumento em suas complexidades estruturais. Esses resultados revelam distintos padrões de articulação entre o setor externo e a estrutura produtiva interna desses países. Os resultados para a economia dos Estados Unidos também revelam um padrão similar aos do Brasil e do México no sentido de que houve um aumento de sua participação nas cadeias de valor e uma queda na complexidade de sua estrutura produtiva. De maneira geral, verificamos uma relação não-linear entre o nível de participação nas cadeias globais de valor e o grau de complexidade das estruturas produtivas.

Os resultados obtidos para o comprimento médio das cadeias produtivas (average propagation lengths) reforçam a percepção de que as estruturas produtivas do Brasil e do México tornaram-se menos complexas, enquanto a da China aumentou sua complexidade estrutura. A fragmentação dos processos produtivos aumentou o comprimento médio das cadeias produtivas da China e de outros países asiáticos, enquanto ocorreu uma diminuição no comprimento médio das cadeias produtivas do Brasil e do México. Isso significa que os efeitos de retroalimentação entre os setores das economias brasileira e mexicana diminuíram nessas economias, provocando, assim, uma redução no comprimento médio das cadeias produtivas desses países. A hipótese que formulamos no presente estudo é a de que essa redução simultânea na complexidade estrutural e no comprimento médio das respectivas cadeias produtivas foi a incapacidade em gerar suficientes encadeamentos entre o setor externo e a estrutura produtiva interna dessas duas economias. 


\section{Referências}

ÁLVAREZ, M. G., PUCHET, M. A. Apertura comercial, grado de integración y estructura de los bloques económicos: el caso de México-Estados Unidos, 1970-2009. In: Puyana, A. (Org.). Paradojas de la globalización y el desarrollo latinoamericano. Ciudad de México: FLACSO, 2015. AMARAL, J. F.; DIAS, J.; LOPES, J. C. Complexity as interdependence in input-output systems. Environment and Planning A, v. 39, n. 7, pp. 1770-1782, 2007.

AROCHE, F. Economic structures in Brazil, Mexico, and South Korea: an input-output application. 1993. 241 f. Tese (Doutorado em Economia) - Queen Mary and Westfield College, University of London, Londres.

BARTELME, D., GORODNICHENKO, Y. Linkages and development. NBER Working Paper, $\mathrm{n}^{\circ}$ $21251,2015$.

BASU, R.; JOHNSON, T. G. The development of a measure of intersectoral connectedness by using structural path analysis. Environment and Planning A, v. 28, n. 4, pp. 709-730, 1996.

BEVERELI, C., et al. Domestic foundations of global value chains. Paper presented at the International Workshop on GVC Development Held in China Development Forum, Beijing, 2016.

BODDIN, D. The role of newly industrialized economies in global value chains. IMF Working Paper, $\mathrm{n}^{\circ} 16,2016$.

BOTT, R., MAYBERRY, J. P. Matrices and trees. In: MORGENSTERN, O. (Ed.) Economic activity analysis. Nova York: Wiley, 1954.

CANUTO, O., FLEISCHHAKER, C., SCHELLEKENS, P. The curious case of Brazil's closedness to trade. Policy Research Working Paper, $\mathrm{n}^{\circ}$ 7228, 2015.

CASTILHO, M., PUCHET, M. Commercial integration and the structure of trade flow in Latin America. In: PUNZO, L., FEIJÓ, C. A., PUCHET, M. (Orgs.). Beyond the global crisis: structural adjustments and regional integration in Europe and Latin America. Reino Unido: Routledge, 2012.

CHENERY, H.; WATANABE, T. International comparisons of the structure of production. Econometrica: Journal of the Econometric Society, pp. 487-521, 1958.

DAUDIN, G., RIFFLART, C., SCHWEISGUTH, D. Who produces for whom in the world economy? Canadian Journal of Economics, v. 4, n 44, pp. 1403-1437, 2011.

DIETZENBACHER, E. The measurement of interindustry linkages: key sectors in the Netherlands. Economic Modelling, v. 9, n. 4, pp. 419-437, 1992.

DIETZENBACHER, E. et al. The construction of World Input-Output Tables in the WIOD project. Economic Systems Research, v.25, pp. 71-98, 2013.

DIETZENBACHER, E. Fragmentation in an Inter-country Input-Output Framework. Working Paper Series, ${ }^{\circ} 5,2013$.

FINN, J. T. Measures of ecosystem structure and function derived from analysis of flows. Journal of theoretical Biology, v. 56, n. 2, pp. 363-380, 1976.

GALA, P. Complexidade econômica: uma nova perspectiva para entender a antiga questão da riqueza das nações. Rio de Janeiro: Contraponto, 2017.

GAZON, J. Transmission de l'influence économique: une approche structurale. Paris: Sirey, 1976.

HERMIDA, C. C. Padrão de especialização comercial e crescimento econômico do Brasil no contexto da fragmentação da produção e das cadeias globais de valor. 2016. 287 f. Tese (Doutorado em Economia) - Faculdade de Economia, Universidade Federal de Uberlândia, Minas Gerais.

HIDALGO, C. A. et al. The product space conditions the development of nations. Science, v. 317, $\mathrm{n}$. 5837, pp. 482-487, 2007.

HIRSCHMAN, A. La estrategia de desarrollo económico. México: Fondo de Cultura Económica, 1961.

HUMMELS, D., ISHII, J., YI, K. M. The Nature and Growth of Vertical Specialization in World Trade. Journal of International Economics, v. 1, nº 54, pp. 75-96, 2001. 
HURWICZ, L.; LEONTIEF, W. Input-output analysis and economic structure. American Economic Review, 45, pp. 626-636, 1955.

JOHNSON, R. C., NOGUERA, G. Acconting for intermediates: Production sharing and trade in value added. Journal of International Economics, $n^{\circ}$ 87, pp. 105-111, 2012.

KOOPMAN, R., WANG, Z., WEI, S-J. Tracing value-added and double counting in gross exports. American Economic Review, v. 104, nº 2, pp. 459-494, 2014.

LANTNER, R. L'analyse de la dominance économique. Revue d'économie politique, $\mathrm{n}^{\circ}$ 82, pp. 216 283, 1972.

Théorie de la dominance économique. Dunod: Paris, 1974.

LANTNER, R.; LEBERT, D. Dominance, dependence and interdependence in linear structures: a theoretical model and an application to the international trade. Documents de travail du Centre d'Economie de la Sorbonne, no 43, 2013.

Dominance et amplification des influences dans les structures linéaires.

Économie Appliquée, v. 68, nº. 3, pp. 143-165, 2015.

LEONTIEF, W. Análisis económico input-output. Barcelona: Ediciones Orbis, 1985.

LOPEZ-GONZALEZ, J. L., MELICIANI, V., SAVONA, M. When Linder Meets Hirschman. InterIndustry Linkages and GVCs in Services. ISI growth Working Paper, $\mathrm{n}^{\circ}$ 1, 2016.

MEDEIROS, C., TREBAT, N. Finance, trade, and income distribution in global value chains: implications for developing economies and Latin America. Instituto de Economia - Texto para Discussão - , nº 002, 2017.

MENG, B. et al. Measuring China's domestic production networks through Trade in Value-added perspectives. Economic Systems Research, v. 29, nº. 1, p. 48-65, 2017.

MILBERG, W., WINKLER, D. Outsourcing economics: global value chains in capitalist development. New York: Cambridge University Press, 2013.

PUCHET, M. Análisis de la integración económica: aspectos del caso EUA-México. In: BIZZOZERO, L., VAILLANT, M. (eds.). La inserción Internacional del Mercosur: ¿Mirando al Sur o Mirando al Norte?. Montevideo: Arca, 1996.

PUCHET, M., SOLÍS, V. Análisis estructural de la industrialización de México y las cadenas globales de valor. Taller de Análisis de Insumo-Producto. Artigo não publicado, 2013.

RASMUSSEN, P. N. Studies in Intersectoral Relations. Amsterdam: North-Holland, 1957.

ROBINSON, S.; MARKANDYA, A. Complexity and adjustment in input-output systems. Oxford Bulletin of Economics and Statistics, v. 35, n. 2, pp. 119-134, 1973.

ROMERO, I., DIETZENBACHER, E. HEWINGS, G. Fragmentation and complexity: analyzing structural change in the Chicago regional economy. Revista de Economía Mundial, $n^{\circ}$ 23, p. 263 282, 2009.

SARTI, F., HIRATUKA, C. Indústria mundial: mudanças e tendências recentes. Texto para discussão: IE/UNICAMP, n $^{\circ}$ 186, 2010.

SONIS, M.; HEWINGS, G. Economic complexity as network complication: Multiregional inputoutput structural path analysis. The Annals of Regional Science, v. 32, n. 3, pp. 407-436, 1998.

SONIS, M., HEWINGS, G. Feedbacks in input-output systems: impacts, loops and hierarchies. In: LAHR, M. L., DIETZENBACHER, E. (Eds.) Input-output analysis: frontiers and extensions. Londres: Palgrave, 2001.

United Nations Conference on Trade and Development. Global Value Chains and South-South Trade: Economic Cooperation and Integration among Developing Countries. Geneva: United Nations, 2015.

WONG, Y. K. Some mathematical concepts for linear economic models. In: MORGENSTERN, O. (Ed.). Economic Activity Analysis. Nova York: Wiley, 1954.

YAN, C., AMES, E. Economic Interrelatedness. The Review of Economic Studies, 32, p. 290-310, 1965. 